SAND97-0689 • UC-704

Unlimited Release

Printed April 1997

\title{
Low Density, Microcellular, Dopable, Agar/Gelatin Foams for Pulsed Power Experiments
}

\section{RECEIVED \\ APR 161997 \\ OSTI}

W. F. McNamara, J. H. Aubert

\section{Prepared by}

Sandia National Laboratories.". "

Albuquerque, New Mexico 87185 and Livermore, California 94550

Sandia is a multiprogram laboratory operáted by Sandia

Corporation, a Lockheed Martin Company,for the United States

Department of Energy under Contract PE AC 494 AL 85000 .

$\therefore$, why

Approved for public release; distribution is unilimited.

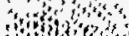

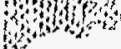

\section{(17) Sandia National laboratotires}
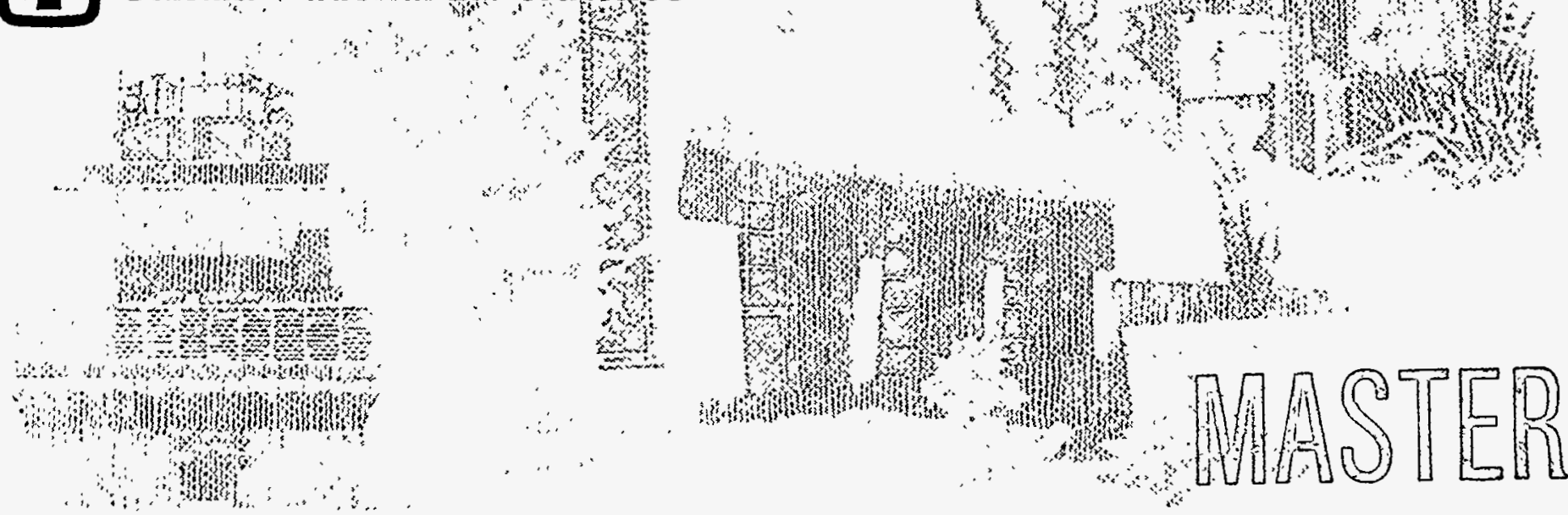
Issued by Sandia National Laboratories, operated for the United States Department of Energy by Sandia Corporation.

NOTICE: This report was prepared as an account of work sponsored by an agency of the United States Government. Neither the United States Government nor any agency thereof, nor any of their employees, nor any of their contractors, subcontractors, or their employees, makes any warranty, express or implied, or assumes any legal liability or responsibility for the accuracy, completeness, or usefulness of any information, apparatus, product, or process disclosed, or represents that its use would not infringe privately owned rights. Reference herein to any specific commercial product, process, or service by trade name, trademark, manufacturer, or otherwise, does not necessarily constitute or imply its endorsement, recommendation, or favoring by the United States Government, any agency thereof, or any of their contractors or subcontractors. The views and opinions expressed herein do not necessarily state or reflect those of the United States Government, any agency thereof, or any of their contractors.

Printed in the United States of America. This report has been repraduced directly from the best available copy.

Available to DOE and DOE contractors from

Office of Scientific and Technical Information

P.O. Box 62

Oak Ridge, TN 37831

Prices available from (615) 576-8401, FTS 626-8401

Available to the public from

National Technical Information Service

U.S. Department of Commerce

5285 Port Royal Rd

Springfield, VA 22161

NTIS price codes

Printed copy: A03

Microfiche copy: A01 


\title{
SAND97-0689 \\ Unlimited Release \\ Printed April 1997
}

Distribution

Category UC-704

\section{Low Density, Microcellular, Dopable, Agar/Gelatin Foams For Pulsed Power Experiments}

\author{
W. F. McNamara \\ Orion International Technologies, Inc., Albuquerque, NM \\ J. H. Aubert \\ Encapsulants and Porous Materials Department \\ Sandia National Laboratories \\ P.O. Box 5800 \\ Albuquerque, NM 87185-1407
}

\begin{abstract}
Low-density, microcellular foams prepared from the natural polymers agar and gelatin have been developed for pulsed-power physics experiments. Numerous experiments were supported with foams having densities at or below $10 \mathrm{mg} / \mathrm{cm}^{3}$. For some of the experiments, the agar/gelatin foam was uniformly doped with metallic elements using soluble salts. Depending on the method of preparation, cell sizes were typically below 10 microns and for one process were below 1.0 micron.
\end{abstract}




\section{DISCLAIMER}

Portions of this document may be illegible in electronic image products. Images are produced from the best available original document. 


\section{Outline}

4..........Introduction

7..........Agar, Agarose, And Gelatin

9..........Agar/Gelatin Foam Development At LLNL: Background

10.........Agar/Gelatin Foam Development At SNL

17........Pulsed Power Experiments Supported At SNL

18........Future Work

22.........Acknowledgements

23........References

25.......Distribution 


\section{INTRODUCTION}

The pulsed power programs at Sandia National Laboratories have had a long-term and ongoing requirement for low-density polymeric foams. For example, the ion-driven inertial confinement fusion program has utilized low-density polymer foams as a converter to absorb the energy of a cylindrically symmetrical ion beam and convert it into spherically symmetrical x-ray radiation as a means to indirect drive of a fusion capsule ${ }^{1}$. Foams have been needed for this and other pulsed power programs which have the following general characteristics: low-density (typical $0.002-0.010 \mathrm{gm} / \mathrm{cm}^{3}$ ), low-atomic-number elements (typical $\mathrm{C}, \mathrm{H}, \mathrm{N}, \mathrm{O}$ ), machinable or moldable, chemically pure (few high-Z contaminants), small cell size (typically under 10 micrometers $(\mu \mathrm{m})$ ), great spatial density uniformity, and dopable with a wide variety of high- $Z$ elements. Numerous low-density, microcellular foams have been developed for similar applications which satisfy many of these requirements ${ }^{2,3}$. However, very few of these foams satisfy all of these requirements. Particularly difficult is the attainment of the ultra-low density requirement of $0.002-0.010$ $\mathrm{g} / \mathrm{cm}^{3}$ and the necessity to dope the foams with numerous high $-Z$ elements. One of the most versatile foam system which satisfies all of these requirements is the agar/gelatin foam system, which was originally developed at Lawrence Livermore National Laboratories ${ }^{4}$, (LLNL).

Other foams which have been used in pulsed power experiments at Sandia include poly-4methyl-1-pentene foams. These foams were purchased first from Los Alamos National Laboratories (LANL) and subsequently from Oak Ridge National Laboratories ${ }^{5}$ (ORNL). The later had a density of approximately $0.005 \mathrm{gm} / \mathrm{cm}^{3}$. They were prepared with a phase separation process ${ }^{2}$ and with a solvent that is a solid at room temperature. The foams were machined to the final dimensions while still solvent-filled. The solvent was removed after the machined piece was put into its experimental configuration. This technique allowed these fairly weak foams to be utilized. A scanning electron photomicrograph of this foam's morphology is shown in Figure $1^{6}$. As can be seen, the cell size is larger than the desired value. Although these

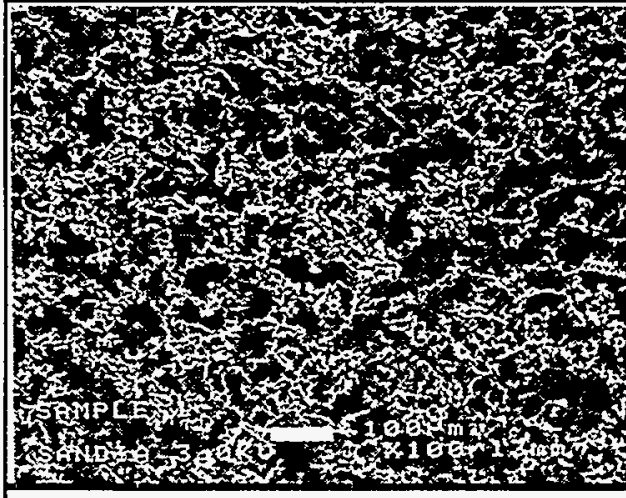

Figure 1. Scanning electron photomicrograph of nominal $0.005 \mathrm{gm} / \mathrm{cm}^{3}$ poly-4-methyl-1pentene foam prepared at ORNL. The bar corresponds to $100 \mu \mathrm{m}$.

foams were not doped, it would have been difficult if this had been required. Polyacrylic acid foams ${ }^{7}$ have also been prepared for pulsed power experiments and meet many of these criteria as could other water soluble polymers, but better mechanical properties can be obtained with agar/gelatin foams.

In addition, carbon foams were prepared for one experiment that required a higher density material. They were prepared by carbonization of polyacrylonitrile foams ${ }^{2}$, but could not be prepared to satisfy the frequent ultra-low-density requirement. Silica aerogels were obtained from LLNL for one experimental series, but do not satisfy the low-Z elemental requirement. In addition, doping of silica aerogels could be problematic. A scanning electron photomicrograph of a $0.003 \mathrm{gm} / \mathrm{cm}^{3}$ silica aerogel used in this experimental series is shown in Figure 2. Numerous foams can be made at higher densities $\left(>0.025 \mathrm{~g} / \mathrm{cm}^{3}\right)^{2,3}$. Although any of these other foams can in principal be doped with high- $Z$ elements, agar/gelatin has the advantage of being doped relatively easily because it is water soluble as 
are many compounds containing high-Z elements (such as water soluble salts). This is the primary reason that agar/gelatin foams were initially investigated by LLNL for similar applications and why we chose to develop them further.

Agar/gelatin foams are prepared through a gelation/phase separation process. Agar/gelatin forms thermally reversible gels in water and also in water/organic solvent solutions such as water/dimethyl sulfoxide, water/N,Ndimethylformamide, water/N-methylformamide, and water/formamide. Gels are frequently classified in two ways: 1) how the gel is held together, and 2) the morphology of the gel. If the polymer chains in the gel are connected by chemical bonds, then the gel is referred to as a chemical gel. Alternatively, if the polymer chains are held together by physical means, such as crystals or hydrogen bonding, then the gel is referred to as thermally reversible. This is due to the fact that slightly elevated temperatures will cause these physical bonds to break and the gel to

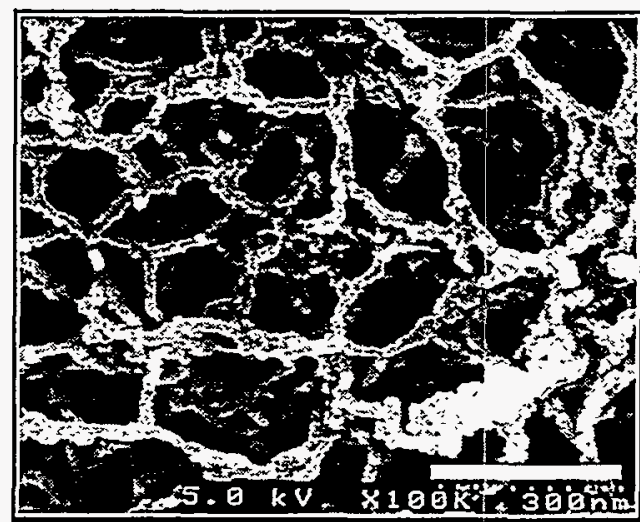

Figure 2. Scanning electron photomicrograph of nominal $0.003 \mathrm{gm} / \mathrm{cm}^{3}$ silica aerogel prepared at LLNL. The bar corresponds to 0.3 $\mu \mathrm{m}$. be destroyed. Agar gels are thermally reversible gels. In terms of morphology, gels are classified as either fishnet or lattice gels, which are shown schematically in Figure 3. Fishnet gels consist of a bicontinuous structure of either individual polymers or small associations of polymer strands that are connected by chemical or physical bonds and are surrounded by solvent. Lattice gels are two phase structures with one phase being continuous and high in polymer concentration and the other

\section{FISHNET GEL}

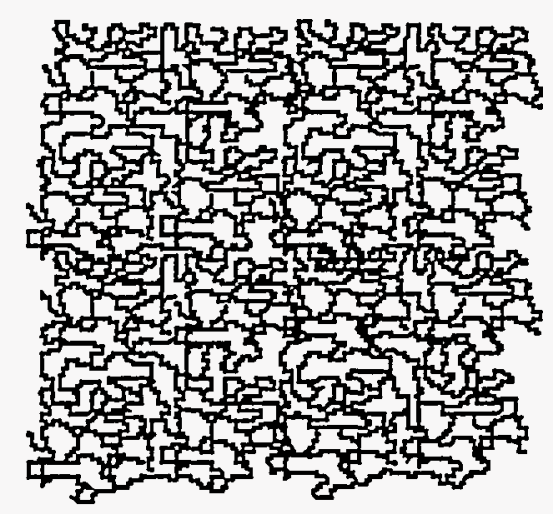

Each thin line represents eithera polymer chain or a small association of polymers

\section{LATTICE GEL}

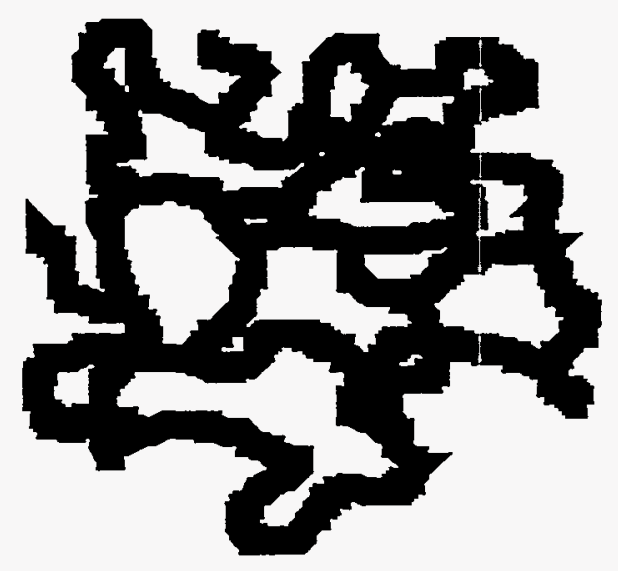

Each thick line represents a polymer-rich phase

Figure 3. Representation of a fishnet and a lattice gel. Polymer is represented as black. The volume fraction of polymer is the same in both gels but is distributed differently: as either individual polymers or small associations of polymers in the fishnet gel and as part of a polymer-rich phase in the lattice gel. The white areas represent either solvent or polymer-poor phase. 
phase being a polymer-poor (solvent-rich) phase which could also be continuous. Agar gels are of the fishnet type. This is important because it determines how the gel can be transformed into a foam.

Fishnet gels cannot be directly formed into a foam by removing the solvent from the gel. Removing the solvent from a fishnet gel would leave individual polymer molecules or small associations of polymer molecules exposed. They have such weak mechanical properties and such a high surface energy that they collapse into a dense phase immediately as the solvent is being removed. Even using a supercritical solvent, with no surface tension, in such a process would not work. There are two approaches that have been used with agar/gelatin gels to allow one to remove the solvent from them and prepare foams. These approaches are summarized in Figure 4. In the first approach, one starts with a fishnet gel and causes a phase separation in it by freezing the solvent. When the solvent is frozen, crystals of solvent grow within the gel and concentrate the polymer to the grain boundaries of the solvent crystals. The frozen gel therefore has a morphology similar to a frozen lattice gel. By subliming the solvent, the phase-separated morphology is maintained. It has sufficient strength since it is a dense phase of agar/gelatin. The morphology of these foams can be controlled to some extent by controlling the solvent freezing process, for example by the temperature. The nascent gel solvent can also be exchanged for other solvents or cosolvents to control the crystallization process and thereby the foam morphology.

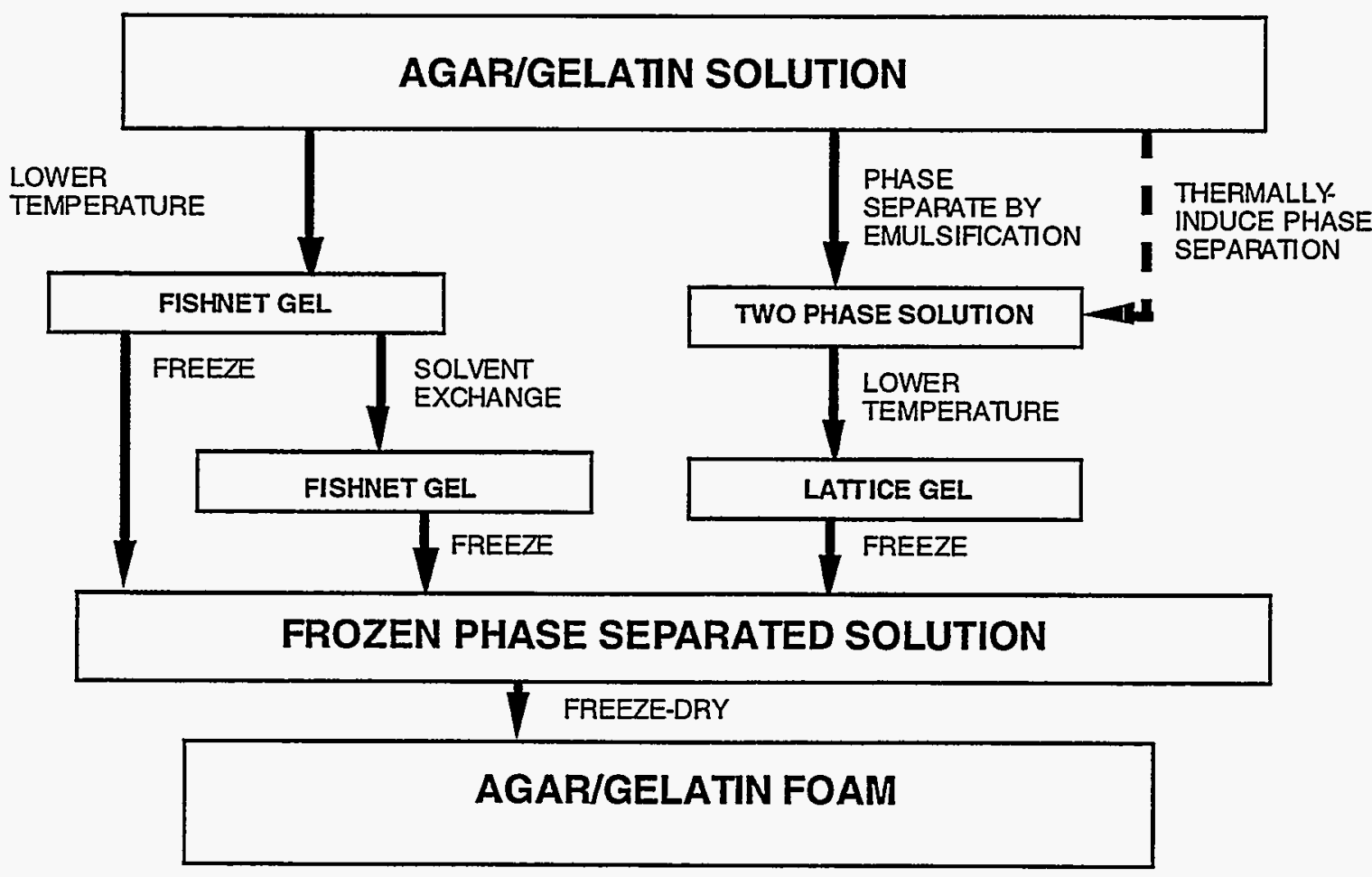

Figure 4. Process diagram depicting the two process schemes used to prepare agar/gelatin foams and a possible third (dashed line). In all processes, phase separation occurs.

The other approach which has been successfully utilized with agar gels is to form a phaseseparated structure in the solution prior to gelation. In this way a lattice gel is formed. This approach was successfully developed by LLNL $^{4}$ by adding a surfactant and an organic liquid to the agar/gelatin solution and preparing an oil-in-water emulsion. The surfactant is 
chosen such that the aqueous phase is continuous. Therefore, when the temperature is lowered, the aqueous phase gels around islands of the organic phase, creating a lattice gel. This gel can then be frozen and both the organic and aqueous phases sublimed. The morphology of this foam can be controlled to some extent by the emulsification which creates the morphology of the lattice gel.

A final approach which could be possible with agar/gelatin, but to our knowledge has not been demonstrated, is to find a solvent such that liquid phase separation occurs prior to gelation (dashed line in Fig. 4). This is the approach that has been successfully demonstrated with many crystallizable polymers ${ }^{2}$. This approach would again lead to a lattice gel which could be frozen and the solvent sublimed to prepare an agar/gelatin foam.

In this report we will describe the successful approaches to preparing agar/gelatin gels for a number of pulsed power target experiments.

\section{AGAR, AGAROSE, AND GELATIN}

Derived from certain red seaweeds, agar is included in the class Rhodophyta (red algae) ${ }^{10}$. It is a mixture of polysaccharides, historically used most frequently as an additive in foods, introduced into Europe and America from China in the middle of the 19th century as a substitute for gelatin in desserts. A German woman, Eilshemius Hesse, first conceived the idea of using agar as a solid bacterial culture medium, and it was subsequently used by her husband, a physician, who in turn passed on the discovery to an associate, Robert Koch; he used agar as a culture medium in his experiments on tuberculosis bacteria and is usually given credit for its discovery in 1882 .

Agar can contain sulfate ester, methoxyl, ketal, pyruvate and carboxyl groups attached to its basic repeating unit: agarobiose. These groups are not always present concurrently, but they can appear on the agarobiose backbone in an almost infinite number of combinations. Thus, agar is essentially repeating units of agarobiose with varying numbers of attached anionic groups mentioned above. In powdered form, agar has a brownish or yellowish color and is slightly hygroscopic. It is easily handled in the laboratory; it should be added to solvents with stirring at or below room temperature in order to avoid clumping.

The basic repeating unit of agar is also that of agarose $\mathrm{e}^{11-16}$. This unit is termed agarobiose and is shown in Figure 5. A practical definition of agarose has been recommended by Duckworth and Yaphe (see general reference on agar): "...that mixture of agar molecules with the lowest charge content and therefore, the greatest gelling ability, fractionated from a whole complex of molecules, called agar, all differing in the extent of masking with charged groups."

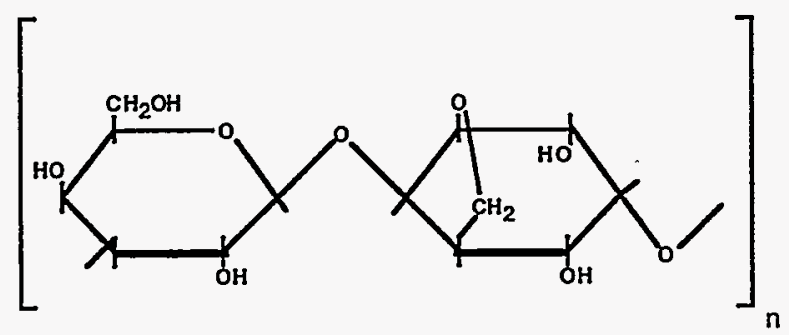

Figure 5. Agarobiose: The fundamental repeating unit of agarose. 
Thus, agarose is essentially a purified form of agar, or one could use the term "deionized" agar, since purification involves removal of most of the anionic species (principally sulfate and pyruvate groups) from agar. Recovery of agarose from agar is based upon differences in solubility and/or chemical reactivity of the anionic groups. Commercially important processes include removal of the more highly sulfated molecules by precipitation with cetylpyridinium chloride or addition of other highly anionic polymers such as carrageenan to increase the bulk of the quaternary ammonium salt precipitate and facilitate removal of anionic species by co-precipitation.

The most common use of agarose today is in biomedical applications, which include electrophoresis, chromatography, immunology and microbiology. Most investigations which utilize agarose involve separation of biologically important molecules, relying on the gel structure or the electronic nature of agarose to effect the separation. In general, the fewer the charged species present, the stronger will be the gel formed from any given agarose. Figure 6 depicts a schematic of the gelation process as a solution of agarose in water is cooled, forming first gel I, a double helix structure, and then gel II, a bundle of these helix structures.

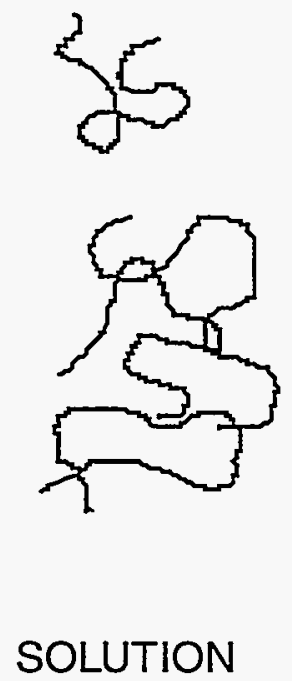

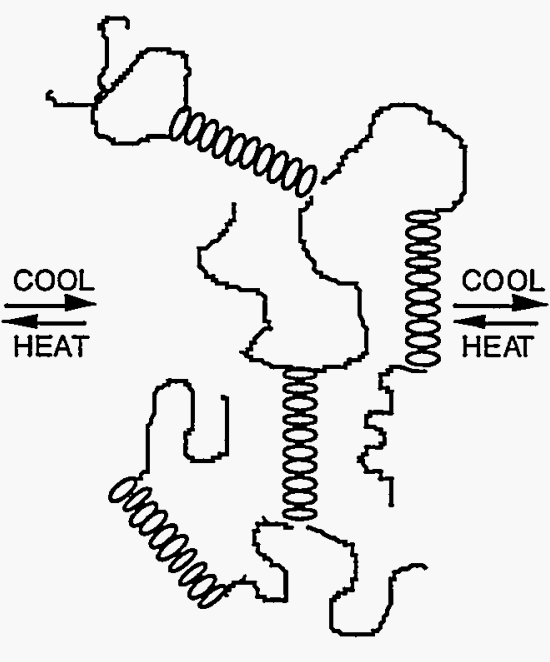

GEL 1

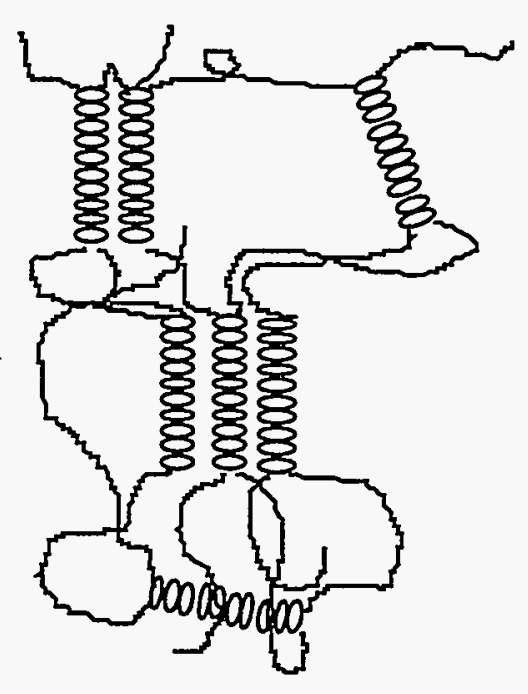

GEL II

Figure 6. Gelation of agarose by formation of double helices connected in three dimensions by zones of random coil configuration.

This is considered a fishnet gel because the bundles are composed of a small number of molecules. A small-pore foam material is not accessible from this fishnet gel by means of extraction of the solvent from the solution; such a procedure would result in certain collapse of the weak structure of the gel. The polymeric material must first be phase separated in order to build up sufficient wall strength in a lattice gel.

The protein comprising the tendons and skin of vertebrate animals is called collagen; it is a water-insoluble fibrous protein ${ }^{17,18}$. Collagen is a polypeptide and contains a large proportion of the cyclic amino acids proline and hydroxyproline, with frequent repetitions of the sequence glycine-proline-hydroxyproline. It consists of three helical polypeptide 
chains wound around each other and connected by intermolecular crosslinks. When collagen is boiled with water, it is converted into the water-soluble protein called gelatin. Gelatin does not occur freely in nature and cannot be recovered from non-collagencontaining parts of vertebrate animals. When cooled, a solution of gelatin in water does not revert back to collagen, rather it sets into a gel.

Plant sources of gelatin do not exist and there is no chemical relationship between gelatin and other materials referred to as vegetable gelatin, such as agar, agarose or carrageenan. Gelatin, along with agar and agarose, is also appropriate for a foam material that can be doped, since it possesses water solubility and thus processability, in addition to structural integrity over the rather long distances of polymeric chains. Therefore, there exists the potential of creating robust material which is mostly empty space.

Mixing of agar and gelatin (1:1) for foam materials to be used in pulsed-power experiments at Sandia National Laboratories (SNL) was chosen solely on the basis of the empirical observations made by R. L. (Bob) Morrison at LLNL during an earlier program there with similar requirements. The resulting material was more robust, easier to cut and machine to final shape and more uniform than any of a wide variety of other water-soluble, gelling polymeric compounds. The elemental analysis of an agar/gelatin foam used at SNL is given below.

\begin{tabular}{cc} 
element & percent-by-mass \\
\hline $\mathrm{C}$ & 45.4 \\
$\mathrm{H}$ & 6.73 \\
$\mathrm{~N}$ & 7.46 \\
$\mathrm{O}$ & 39.24 \\
$\mathrm{Na}$ & 0.39 \\
$\mathrm{~S}$ & $\underline{0.78}$ \\
& 100.00
\end{tabular}

\section{AGAR/GELATIN FOAM DEVELOPMENT AT LLNL: BACKGROUND}

The sole source of details about the relevant program at LLNL has been multiple telephone conversations (July 1993 to October 1996) and two meetings (July 1993 and June 1995) with Bob Morrison, the senior research scientist who led the effort to synthesize foams of low density with very small cell sizes. Morrison has authored one account of the general physical and chemical properties of the materials; in addition, several potential applications are enumerated ${ }^{19}$. However, there have been no published accounts in the professional literature of any of the details of the procedure, properties or data obtained and Bob Morrison has informed us that all records of this work at LLNL have been discarded. One purpose of this SAND report is to provide at least a "skeletal" record of the work done at LLNL and to illustrate subsequent further developments at SNL.

According to Bob Morrison, this work was performed at LLNL between 1983 and 1991. The requirements were that the foams have cell sizes on the order of 5 microns or less and specified densities ranging from $70 \mathrm{mg} / \mathrm{cm}^{3}$ down to $6 \mathrm{mg} / \mathrm{cm}^{3}$, the majority of which were 25 to $50 \mathrm{mg} / \mathrm{cm}^{3}$. In addition, the materials had to be able to be doped with various amounts of any non-radioactive element in the periodic table; they also had to be robust and possess excellent uniformity throughout so that they could be machined into intricate shapes. Machining of the material is possible at a density of $6 \mathrm{mg} / \mathrm{cm}^{3}$ and it becomes 
routine at 10 to $15 \mathrm{mg} / \mathrm{cm}^{3}$ and higher. The requirement of dopability meant that the polymeric materials had to be water-soluble, since dissolution of easily obtainable watersoluble salts of the elements of interest was the easiest method by which to dope the foams with the greatest possible uniformity. Nevertheless, very finely divided dopants were used in some cases, if they could be suitably dispersed; examples include $\mathrm{TiO}_{2}$ for doping with titanium and finely divided (particle size 0.9 micron) tungsten.

A very large variety of gelling agents was investigated by Bob Morrison and his coworkers in an attempt to meet the above-mentioned requirements; these included various types of agar, agarose, industrial gums, carrageenan and various gelatins. Finally, the material of choice proved to be bacteriological-grade agar (Polysciences) and unflavored gelatin (Knox, available at most food stores) in a ratio of $1: 1$. This was the material used for densities ranging from approximately $6 \mathrm{mg} / \mathrm{cm}^{3}$ to a maximum of approximately 50 $\mathrm{mg} / \mathrm{cm}^{3}$. Attempts were made to produce foam of density near $1 \mathrm{mg} / \mathrm{cm}^{3}$. The lowest attainable density was $1.2 \mathrm{mg} / \mathrm{cm}^{3}$; this was possible with a material called Gelrite $®$ gellan gum (Gelrite is a registered trademark of Monsanto Company; Phytagel ${ }^{\mathrm{TM}}$ is the name of the product (no. P 8169), available from Sigma Chemical Company).

The generalized procedure used by Morrison and co-workers follows: A calculated amount of agar and gelatin (1:1), depending upon desired final density and accounting for shrinkage of the product during drying, was weighed out and added slowly to a measured amount of water at room temperature with stirring in order to avoid clumping. The mixture was heated with stirring to $85^{\circ}$ to $90^{\circ} \mathrm{C}$ and held at that temperature until complete dissolution of the solids was achieved. At this point, the hot solution and container were placed onto a balance and weighed in order to replace the water lost during heating. Stirring of the solution was then continued while a small amount (approximately 2\%-byvolume with respect to the final total volume) of an anionic surfactant (10\%-by-mass aqueous solution of Triton GR-5M, Union Carbide) and p-xylene (one-third of the final total volume) were added. While the solution was still well above $80^{\circ} \mathrm{C}$, it was subjected to high-shear homogenization to create an oil-in-water emulsion in which the continuous phase was the aqueous solution of agar and gelatin. The emulsion was poured into molds and allowed to gel in an ice water bath and subsequently frozen quickly at $-80^{\circ} \mathrm{C}$; the molds were then placed into a freeze dryer where the solvents (water and p-xylene) were completely removed by means of a dynamic vacuum at a temperature below their freezing point over a period of a few days. The freeze drying step allows removal of the solvents without disturbing the foam structure established upon creation of the emulsion. Bob Morrison has stated that cyclohexane can be used in place of p-xylene for the organic phase; in addition, the choice of surfactant was one of availability of the Triton GR-5M at LLNL at that time, rather than the result of any testing.

After lyophylization in the freeze dryer, the "bricks" of foam could be cut, shaped, sawed and sliced to the desired dimensions for the relevant physics experiments.

\section{AGAR/GELATIN FOAM AND PROCESS DEVELOPMENT AT SNL}

The simpliest approach to prepare an agar/gelatin foam is to freeze an agar/gelatin gel (or just an agar gel) prepared in water and to remove the water through sublimation. Figure 4 depicts this simple approach and a process to prepare this foam is described in the sidebar as Procedure 1. An SEM photomicrograph of an agar foam prepared in this-way is shown 
in Figure 7. The foam morphology is seen to be directional and the cell sizes are as large as several hundreds of microns. This is really an unacceptable way to prepare a quality foam, but is included for completeness. Drastically improved morphologies can be obtained with little increase in complexity by exchanging the water in the gel with a cosolvent, which results in a smaller crystal size upon freezing. We have done this with a mixture of $55 \%$ water and $45 \%$ 1,4-dioxane. This cosolvent was chosen because it exhibits no volume change upon freezing?. Constrast this to water which expands upon freezing and 1,4-dioxane which contracts upon freezing. A process to prepare a foam in this way is described in the sidebar as Procedure 2, and an SEM photomicrograph of the foam is shown in Figure 8 . The cell size is seen to be very uniform and less than one micron in size. Note that the foams depicted in both Figures 7 and 8 are the same density, approximately $0.010 \mathrm{~g} / \mathrm{cm}^{3}$. However, the cell size is two orders of magnitude smaller when the cosolvent is used as opposed to just water. This is a general way to control cell size and morphology with this process, i.e., one controls the solvent crystallization. A great deal of work could be done here to optimize this method of preparing agar or agar/gelatin foams.

This method of preparing agar or agar/gelatin foams is very amenable to the molding of foams to specific shapes. This is due to two reasons. First, a very low density (and low viscosity) liquid is used initially (prior to gelation) which is easy to fill into a mold. And second, the cosolvent utilized has no volume change upon freezing (isochoric), so that the frozen gel should have exactly the same volume as the mold. Some preliminary work has been done to investigate molding these foams to shape with good success. Figure 9 shows examples of cylinders that were molded to shape. This process does not insure that the dry foam has exactly the same volume as the mold, since there is also shrinkage upon drying.

PROCEDURE 1
Dissolve $0.5 \mathrm{gm}$ of
Agar (Fluka
Biochemika, cat
\#05039) in $50 \mathrm{~cm}^{3}$
of distilled water at
$100^{\circ}$ C.
Gel at $0^{\circ}$ C.
Freeze the gel at
$-10^{\circ}$ C.
Sublime the water
from the frozen gel
at $-10^{\circ}$ C.

\section{PROCEDURE 2}

Prepare the gel as in Procedure 1.

Exchange the water in the gel with a mixture of $55 \%$ water and $45 \%$ 1,4dioxane by soaking.

Freeze the gel at $-30^{\circ} \mathrm{C}$.

Sublime 1,4-dioxane at $-30^{\circ} \mathrm{C}$ first and then water at $-10^{\circ} \mathrm{C}$ from the frozen gel.

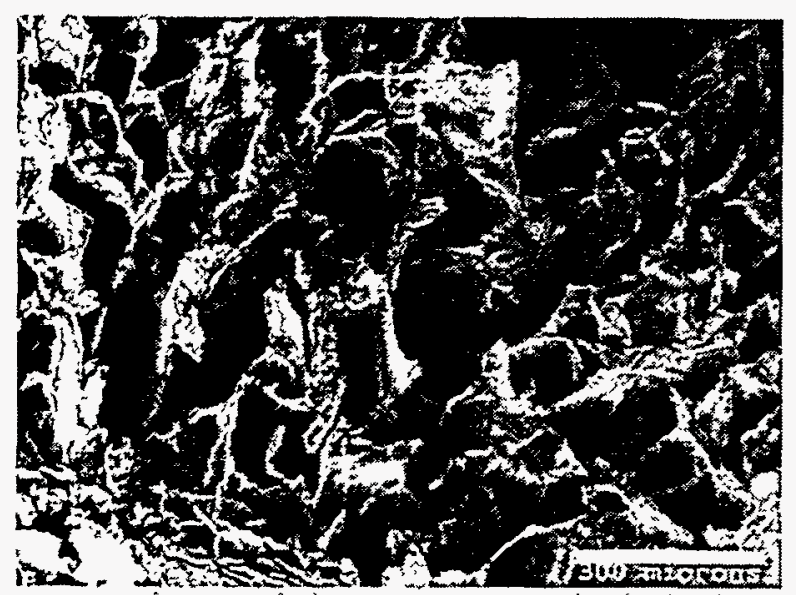

Figure 7. Scanning electron photomicrograph of nominal $0.010 \mathrm{gm} / \mathrm{cm}^{3}$ agar foam (Procedure 1). The bar corresponds to $300 \mu \mathrm{m}$.

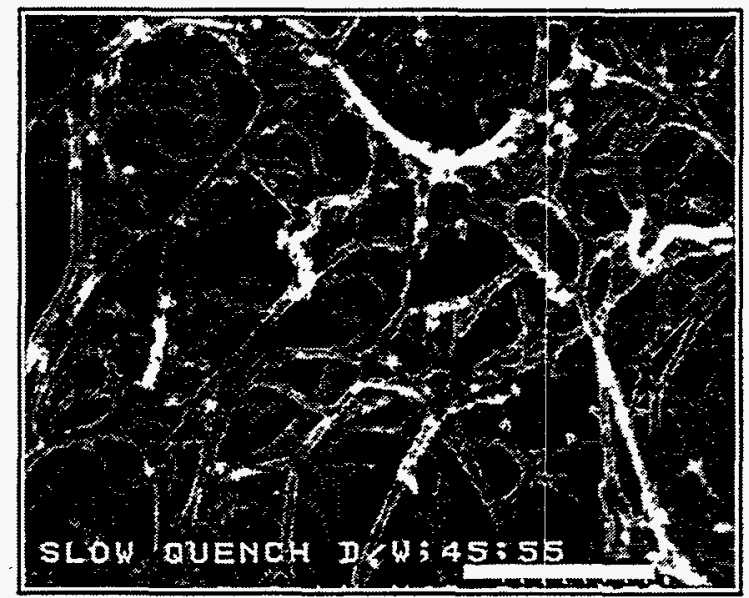

Figure 8. Scanning electron photomicrograph of nominal $0.010 \mathrm{gm} / \mathrm{cm}^{3}$ agar foam (Procedure 2). The bar corresponds to $0.75 \mu \mathrm{m}$. 
A second approach to preparing an agar/gelatin foam is the emulsion process depicted in Figure 4. In the following description of the emulsion process, reference will be made to work done at LLNL by Bob Morrison and co-workers. In addition, departures from their procedures, devised during the development of foam production for pulsed-power experiments at SNL, will be mentioned.

GENERATION OF EMULSION The initial mixing and heating of agar and water was done with a magnetic stirrer/heater in work at LLNL. This is sometimes unreliable, especially with higher density foams, since the stir bar can spontaneously stop in higher viscosity solutions. Attempts to perform this stirring with a mechanical stirrer proved much more cumbersome and problematic. Eventually, magnetic stirrer/heaters with stronger magnets were

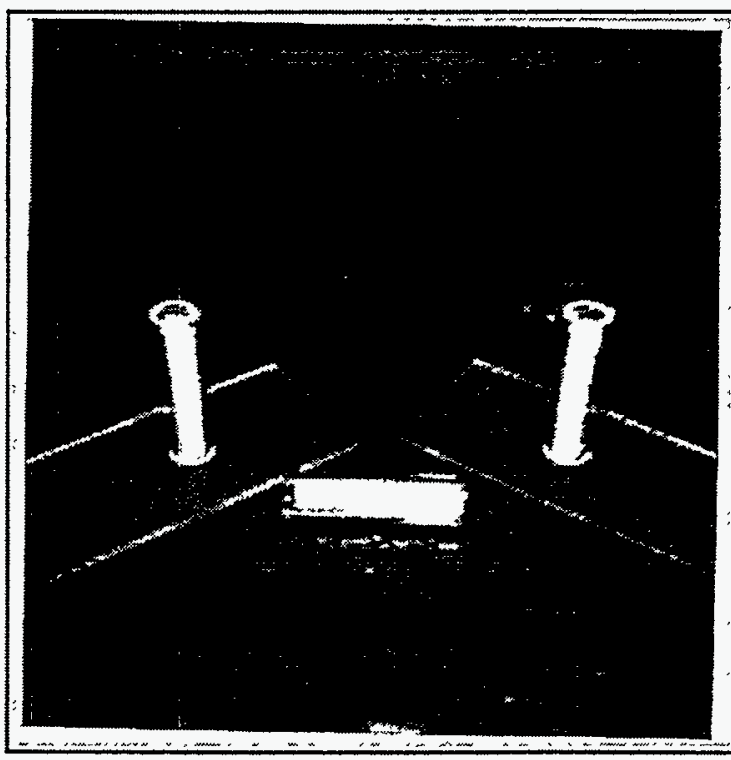

Figure 9 Examples of cylinders that were molded to shape with the isochoric solvent (Procedure 2).

purchased (IKAMAG® RET digi-visc from IKA® Works, Inc.) and the process was much easier.

Creation of an oil-in-water emulsion of the agar/gelatin system is a straightforward method to rapidly produce a material with a foam-like morphology with the proper cell size for the experiments and with sufficient strength for further handling and machining. This is why Bob Morrison and co-workers at LLNL eventually used this procedure for all foams made for their experiments; it was necessary to try many different types of gelling polysaccharides, dopants and ratios of aqueous to organic material, and the emulsion approach allows one to evaluate many possibilities rather rapidly. The emulsion is termed oil-in-water because the aqueous solution with the dissolved agar and gelatin is the continuous phase and the organic solvent ( $p$-xylene or cyclohexane) is the non-continuous or "oil" phase. If there is no surfactant present, mixing of these liquids in a container would simply result in a two-phase system with the organic solvent in a layer above the aqueous solution. The surfactant used by the group at LLNL was Triton® GR-5M, a solution of sodium dioctyl sulfosuccinate in water and 2-propanol (solvents). It is an anionic surfactant from Union Carbide with good wetting, emulsifying and dispersing qualities and it is water-soluble. As one tries to make foams of very low density (less than $10 \mathrm{mg} / \mathrm{cm}^{3}$ ), the amount of surfactant relative to the amount of agar/gelatin becomes larger and the surfactant begins to make up an exaggerated amount of the total material which makes the foam. Thus, one would like to minimize the amount of surfactant in the final solution.

Other surfactants have been tried in attempts to minimize the amount used. These include Tergitol $®$ surfactants from Union Carbide and Zonyl $®$ and Merpoiß surfactants from DuPont. Sufficient testing was never done in order to determine an optimum surfactant or surfactant system. Each polymeric material (agar, agarose, gelatin, etc.) probably has an optimum surfactant best suited to the overall system in question, but the one used by the LLNL group (Triton® GR-5M) exhibited good overall behavior.

As in the work done at LLNL, emulsification of the hot mixture of agar, gelatin, surfactant, dopants (if present) and water was done with a model T 25 Ultra-Turrax $®$ disperser with 
dispersing element $S 25 \mathrm{~N}-25 \mathrm{~F}$ from IKA Works®. For later foam production runs requiring larger volumes of material, a model $\mathrm{T} 50$ Ultra-Turrax disperser with dispersing element S $50 \mathrm{~N}$ - G $45 \mathrm{FF}$ was used, also from IKA Works®. These dispersers and dispersing elements allowed attainment of the minimum droplet size in the emulsion, a morphology which subsequently produced a foam with the smallest attainable cell size.

GELATION AND FREEZING After pouring the hot emulsion into several roomtemperature molds to the proper height ( 1 to $3 \mathrm{~cm}$., depending upon desired final product), they were cooled to approximately $5^{\circ} \mathrm{C}$ in ice water for about 40 minutes; the water was able to flow around and under the molds because of small screws placed at the bottom corners of each mold, raising each mold off the bottom of the pan used for cooling. During this time, gelation occurred. Each mold was covered with a piece of plate glass to avoid contamination and to view any changes. After gelation was complete, Bob Morrison and co-workers at LLNL set each mold into a container and poured ethanol cooled to $-80^{\circ} \mathrm{C}$ around the outside bottom of the mold in order to monodirectionally freeze the material very rapidly; this provided smaller ice crystals and thus a smaller cell size. If the freezing is not monodirectional, from the bottom up, shrinkage causes non-uniformities in the bulk material. The molds used at LLNL generally consisted of a piece of copper plate for the bottom (thickness approximately one-eighth inch) and four side walls of stainless steel welded vertically to the copper bottom (approximate dimensions: length 8 inches, width 3 inches, height 1.5 inches). The stainless steel walls were relatively insulating, compared to the copper bottom, thus allowing for less heat transfer through the sides of the mold.

The molds initially used in the work at SNL consisted of opened-top boxes which had been machined from solid blocks of aluminum; the walls and bottom were all about threesixteenths inch thick, the overall length was about 8.5 inches, the width 4.5 inches and the height 1.25 inches; with a one-inch-wide fill of RTVB sealant on the inside, this left a cavity for the foam material with the approximate dimensions 6 inches by 2 inches. The insulating portion of Dow Corning RTV® sealant was present on the inside of each "box" only at the perimeter, leaving only the center of each box available as a cavity into which the emulsion could be poured, Figure 10. This provided true monodirectional cooling, since the foam material was exposed to the very low temperature through only the bottom of the mold where the aluminum was exposed to the cryogenic liquid; the four sides of the cavity, and thus the sides of the foam "brick" itself, were insulated by the RTV sealant.

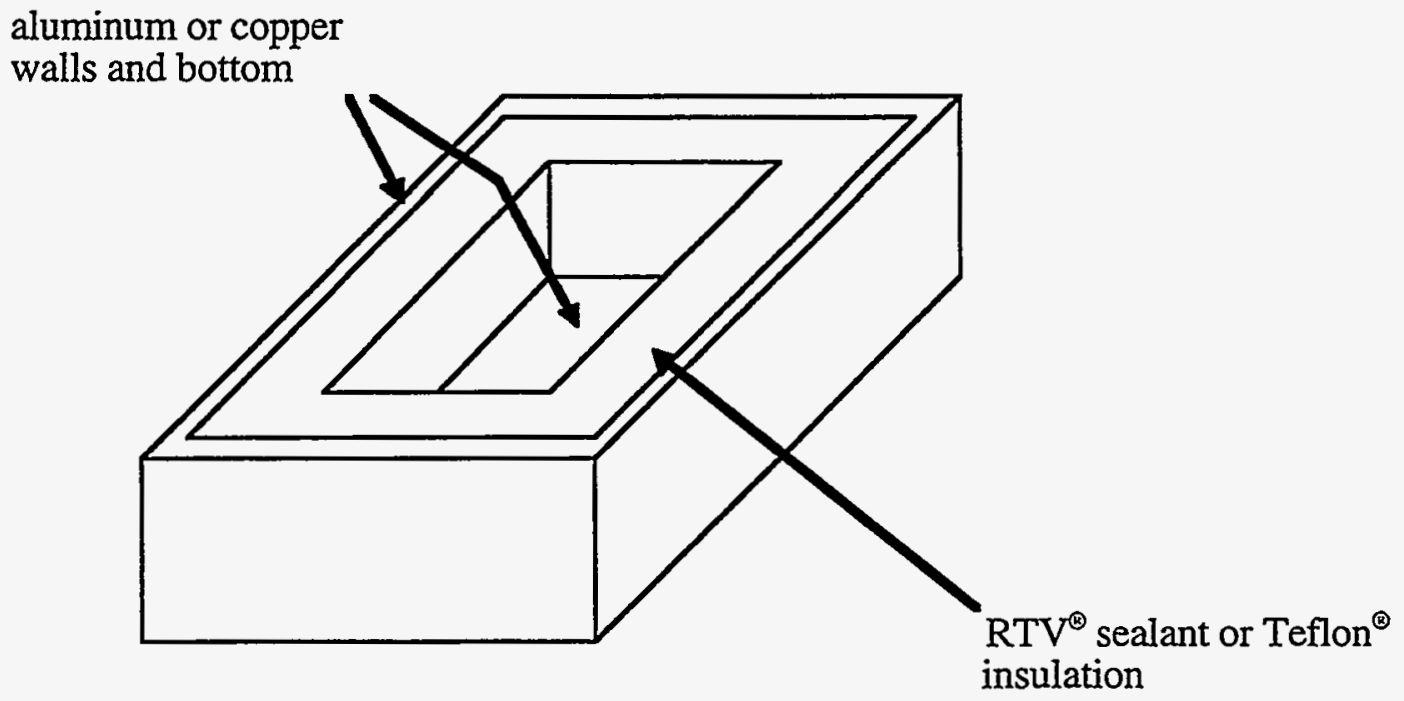

Figure 10. Schematic diagram of mold. 
The method of freezing the foam material in the SNL work also departed from that used at LLNL. The cryogenic liquid was a slush of Fluorinert $\circledast$ FC-77 and dry ice, made by adding small portions of powdered dry ice to a vacuum-insulated glass container about onehalf full of Fluorinert ${ }^{B}$ FC-77. Addition is continued until the consistency is that of a thick "malt", i.e., a thick slush. The slush was then poured into a larger bath, into which the molds were placed for freezing of the foam material. The dry ice was powdered by an ice crusher from Clawson Machine Co.

It was observed during the fabrication and analyses of these foam materials that faster freezing produced superior uniformity and even smaller cell sizes. Bob Morrison and coworkers at LLNL had also made this observation. The foam quality is improved by lower quench temperatures and faster conduction of heat from the mold. A bath of liquid nitrogen for the molds would be safe, but immersion of the molds directly into liquid nitrogen would not provide good mold-to-coolant contact, since the rapidly boiling liquid nitrogen would leave a mold/gas interface instead of a mold/liquid one. The lowest attainable temperature for a liquid coolant bath is a slush of isopentane (2-methylbutane) and liquid nitrogen, which will reach $-160^{\circ} \mathrm{C}$ at equilibrium ${ }^{20}$. This approach was attempted in the program at SNL, but it was eventually abandoned for two reasons; first, the flash point of isopentane is $-56^{\circ} \mathrm{C}$, making it somewhat hazardous to use; secondly, it is very difficult to produce and maintain a useable slush in a relatively opened bath for a sufficiently long time to freeze the foam material in its mold.

In order to solve these problems, it was decided to use all-copper molds, machined from solid blocks of copper, and to use Teflon as the insulating material at the sides of the foam material inside the copper "box". The walls and bottom of the copper molds were only one-eighth inch thick to allow rapid heat conduction while maintaining strength. The molds were 8 inches in length, 4 inches wide and 2 inches in height; there was a one-half-inchwide portion of Teflon machined to slip fit into the copper "box" and be flush at the top; in this manner, the Teflon insulators could be removed after freezing the foam material to allow more rapid removal of solvents during freeze drying or to allow removal of the block of frozen foam material from the box. In conjunction with the copper boxes, solid copper blocks of the same length, width and height were used as a heat sink material; each one had three threaded holes drilled and tapped into the bottom, at two corners on a length and at the midpoint of the opposite length, so that leveling screws could be used as the three legs, allowing coolant to flow underneath the block. This permitted safe cooling of the heat-sink block to the temperature of liquid nitrogen $\left(-196^{\circ} \mathrm{C}\right)$. However, the best possible contact between the copper face of the bottom of a mold (approximately $0^{\circ} \mathrm{C}$ to $5^{\circ} \mathrm{C}$ after gelation of the foam material) and the cooled heat-sink block (approximately $-190^{\circ} \mathrm{C}$ ) had to be ensured. This was done by having the bottom of each mold "box" and the top of each cooling block lapped to a flatness of 0.0002"; in addition, a one-inch-thick solid copper cover block of the same length and width as the copper cooling block was lapped to the same flatness on one of its 8 " $x$ 4" faces. The lapped lower face of the cover block was placed directly onto the lapped upper face of the cooling block before cooling the "matched" blocks of copper from room temperature to the temperature of liquid nitrogen (about one hour) in order to prevent formation of a layer of ice on the top surface of the cooling block, compromising intimate contact between the cooling block and the mold box. In a typical procedure, the temperature of the copper cooling block ( 8 " $\times$ 4" $\times$ 2") and its copper cover block (8" $\times 4$ " $\times 1$ ") would be lowered by placing the cooling block with its three legs into a Nicer® lab pan, placing the lapped face of the cover block over the lapped top surface of the cooling block and maintaining the level of liquid nitrogen in the pan at about halfway up the thickness of the two-inch-thick copper cooling block. When the temperature of the top of the cover block reached about $-190^{\circ} \mathrm{C}$ (tested by a type $\mathrm{E}$ probe thermocouple from Omega $(B)$, the cover block was removed and the mold with its lapped bottom and Tefloninsulated gelled foam material within was quickly placed onto the lapped top of the cooling 
block. When the material was completely frozen, tested by tapping a stirring rod on the top surface of the foam, the entire mold box was placed into the Labconco freeze dryer for removal of all solvents by sublimation. There were some problems with cracking at this low temperature, but the cracks were not visible during the freezing process, although definite cracking sounds could be heard emanating from the foam material during this time, suggesting large amounts of stress and stress relief. The cracks were visible only after the freeze drying process was complete. In future work, the cooling blocks could be cooled to temperatures that are not as extreme, for example $-120^{\circ} \mathrm{C}$ or $-150^{\circ} \mathrm{C}$ to prevent cracking of the foam material if the bricks must be used as whole pieces.

Regardless of what density foam material is desired for the final product in the range of 3 $\mathrm{mg} / \mathrm{cm}^{3}$ up to about $50 \mathrm{mg} / \mathrm{cm}^{3}$, the same fundamental procedure is followed in order to create the emulsion and subsequently freeze the solution and remove the solvents. Densities lower than this require special starting materials, e.g., gellan gum; see the section about foam development at LLNL. Densities higher than about $50 \mathrm{mg} / \mathrm{cm}^{3}$ are essentially impossible to prepare because it is difficult to dissolve the required proportions of agar and gelatin in the hot water. The presence or absence of dopants does not affect the procedure greatly, except that quantities must be adjusted so that the proper percentages of dopant element(s) will be achieved. In cases where relatively dense solid particle dopants were used, such as elemental tungsten or molybdenum, settling of the solid particulate material was problematic; in order to increase the viscosity and reduce settling, the temperature of the agar/gelatin solution had to be allowed to decrease to about $60^{\circ} \mathrm{C}$ before emulisification with the high-shear homogenizer and held there before pouring the emulsion into the molds. This is in contrast to a pour temperature of $80^{\circ} \mathrm{C}$ to $90^{\circ} \mathrm{C}$ for other batches with soluble dopants and in the case of titanium dioxide solid as dopant, where settling was not a problem.

PROCEDURE 3: Agar/gelatin foam of density $10 \mathrm{mg} / \mathrm{cm}^{3}$ doped with sodium tungstate dihydrate $\left(\mathrm{Na}_{2} \mathrm{WO}_{4} \cdot 2 \mathrm{H}_{2} \mathrm{O}\right)$ so that the level of elemental tungsten is $12 \%$-by-mass.

First, the height to which each mold cavity will be poured with hot emulsion must be determined; the thinner the foam usually the better will be the final product, since the freezing can be completed faster. Once the height is known, the initially poured volume of foam material can be calculated by means of the other dimensions of the molds. In addition, the initially poured volume must be to a height greater than the required height, in order to account for shrinkage of the material during freeze drying. The basis for this batch (number 020 ) was 450 milliliters; the ratio of aqueous phase to organic phase was two-thirds to one-third, respectively, by-volume. Thus, $300 \mathrm{ml}$ deionized water and $150 \mathrm{ml}$ p-xylene were used, ignoring the volume occupied by the dissolved agar, gelatin and dopant. Shrinkage was estimated to be about $25 \%$ (Bob Morrison), thus the final volume of dried foam material should be $337.5 \mathrm{ml}$; at $10 \mathrm{mg}$ of foam material per $\mathrm{cm}^{3}$ of volume, this means $3.375 \mathrm{gm}$ will be the final mass of the dry foam material (agar, gelatin and sodium tungstate), ignoring the mass of the surfactant. A total of $12 \%$ of the mass must be elemental tungsten or $0.405 \mathrm{gm}$. The non-dopant material must have a mass ratio of $1: 1$ agar/gelatin.

By calculations, a mixture of 1.32 gm agar (product 28,289-8, Aldrich Chemical Co.), 1.32 gm gelatin (product G2500, the highest gel strength or "bloom" number available from Sigma Chemical Co.), 0.73 gm sodium tungstate dihydrate (product 93-7422, Strem Chemical Co.) and $300 \mathrm{ml}$ deionized water was first weighed in a $1000-\mathrm{ml}$ beaker with a magnetic stir bar and then heated with stirring until all the solid material dissolved (the solids must be added at room temperature with rapid stirring to avoid clumping). In order to replenish the water lost during heating, the beaker and contents were reweighed and hot $\left(80^{\circ}\right.$ to $\left.90^{\circ} \mathrm{C}\right)$ water was added to bring the mass up to the value noted before heating. While still hot $\left(80\right.$ to $\left.90^{\circ} \mathrm{C}\right)$, an aqueous solution of Union Carbide's Triton GR-5M anionic surfactant ( $8 \mathrm{ml}$ of a $10 \%$-by-mass solution in water) and $150 \mathrm{ml}$ of p-xylene were added so that an oil-in-water emulsion of the entire mixture could be made with a high-speed, high-shear homogenizer ( $T 50$ Ultra-Turrax ${ }^{\odot}$ disperser with shaft and rotor/stator element S 50 N G 45 FF from IKA Works (a T 25 Ultra-Turrax ${ }^{\circ}$ with an S $25 \mathrm{~N}$ - 25F disperser and SR 25 beater rotor would also be adequate). The homogenization was performed 
for a sufficiently long period (approximately one minute) in order to achieve minimum droplet size in the emulsion; this ensures minimum pore size in the morphology of the final foam.

After homogenization, portions of the hot emulsion (total volume approximately $450 \mathrm{ml}$ ) were poured into two molds (one-eighth-inch thickness copper-bottomed with one-half-inch insulating walls of Teflon) to the proper height; each mold was initially at room temperature. Water between 0 and $5^{\circ} \mathrm{C}$ was allowed to flow around and under each mold for a period of about 45 minutes, during which the material in the molds formed a gel that set firmly. The molds were taken from the ice-water bath, dried on the bottom and placed directly into a bath of coolant at $-80^{\circ} \mathrm{C}$ (slush of Fluorinert FC-77 in powdered dry ice) where the solvents (p-xylene and water) froze solidly after about 45 minutes. After each portion of material was solidly frozen in its mold, the mold with the material was placed into a Labconco freeze dryer with a stoppering tray dryer, where a vacuum of approximately 10 millitorr was applied at a temperature of about $-8^{\circ} \mathrm{C}$ so that the water and p-xylene would sublime from each brick.

Removal of all solvents from each brick of material required 5 to 10 days of continuous freeze drying. The progress of the freeze drying was monitored by observing the loss in mass of selected bricks. When the loss in mass of a brick was observed to be zero after an overnight period in the freeze dryer, it was deemed finished; the bricks were stored in dry boxes with desiccant until needed for further characterization, processing or machining.

Routine characterization entailed an estimation of the density of each brick, scanning electron micrographs of a representative section from each brick and a radiograph of each brick; determination of the density was easier if equipment was available to cut off or machine off some material on each of the six faces of each foam brick in order to eliminate surface effects from the mold material. The mass of the brick divided by the volume then provides the density.

Scanning electron micrographs allow a view of the morphology of the foam material and an estimation of the cell size. The usual procedure was to immerse an entire brick of foam into liquid nitrogen with tongs or pliers and break it when fully frozen. The undeformed fractured-while-frozen face was then imaged by the scanning electron microscope to obtain a judgment of the quality of the foam.

Radiography provided information about the uniformity of each brick. Some bricks which otherwise may have been sent for machining into shapes were rejected because of variations in the density in the interior of the material.

More involved characterization included elemental analyses of the foam material and ion microtomography (Arlyn Antolak at SNL/CA) of final shapes of the foam in order to view any density variations before being used in pulsed power experiments in addition to seeing elemental variations.

PROCEDURE 4: Agar/gelatin foam of density $35 \mathrm{mg} / \mathrm{cm}^{3}$ doped with titanium dioxide so that the level of elemental titanium is $30 \%$-by-mass.

The volume upon which this batch (number 005 ) was based was 412.5 milliliters. Thus, 275 ml deionized water and $137.5 \mathrm{ml}$ p-xylene were used, ignoring the volume occupied by the dissolved agar, gelatin, dopant and surfactant. Shrinkage was estimated at about $15 \%$ (Bob Morrison), so the final volume of dried foam material should be $350.6 \mathrm{ml}$; at $35 \mathrm{mg}$ of foam material per $\mathrm{cm}^{3}$ of volume, this means $12.25 \mathrm{gm}$ will be the final mass of the dry foam material (agar, gelatin and titanium dioxide), ignoring the mass of the surfactant. A total of $30 \%$ of the mass must be elemental titanium and the non-dopant material must have a mass ratio of $1: 1$ agar/gelatin.

By calculations, a mixture of $3.06 \mathrm{gm}$ agar, $3.06 \mathrm{gm}$ gelatin, $6.12 \mathrm{gm}$ titanium dioxide and $275 \mathrm{ml}$ deionized water was heated with rapid stirring until dissolution was achieved. Subsequently, 4 to $5 \mathrm{ml}$ of surfactant solution were required to achieve a stable emulsion. The remainder of the procedure is identical to the one that appears above.

PROCEDURE 5: Agar/gelatin foam of density $25 \mathrm{mg} / \mathrm{cm}^{3}$ with no dopant.

The volume upon which this batch (number 024) was based was 475 milliliters. Thus, 316.7 ml deionized water and $158.3 \mathrm{ml} \mathrm{p}$-xylene were used, ignoring the volume occupied by the dissolved agar, gelatin and surfactant. Shrinkage was estimated at about $20 \%$ (Bob Morrison), so the final volume of dried foam material should be 380 
$\mathrm{ml}$; at $25 \mathrm{mg}$ of foam material per $\mathrm{cm}^{3}$ of volume, this means $9.5 \mathrm{gm}$ will be the final mass of the dry foam material (agar and gelatin), ignoring the mass of the surfactant. The material must have a mass ratio of 1:1 agar/gelatin.

By calculations, a mixture of $4.75 \mathrm{gm}$ agar, $4.75 \mathrm{gm}$ gelatin and $275 \mathrm{ml}$ deionized water was heated with rapid stirring until dissolution was achieved. Subsequently, $9.5 \mathrm{ml}$ of surfactant solution were required to achieve a stable emulsion. The remainder of the procedure is identical to the one that appears above.

\section{PULSED POWER EXPERIMENTS SUPPORTED AT SNL}

During the course of this work at SNL, a total of 38 batches of foam were produced for eventual use in pulsed-power studies or for experimentation on foam fabrication methods (variations in density, dopant, polymeric material or surfactant); foams were delivered for four separate pulsed-power experimental efforts. All were fabricated in a manner similar to the procedures given in the previous section. The four contributions are outlined below.

\section{Experimenter: Tom Nash}

Required foam: $35 \mathrm{mg} / \mathrm{cm}^{3}$ agar/gelatin (1:1) doped with titanium dioxide to a level of $30 \%$-by-mass elemental titanium

The foam material was provided in the form of bricks of approximate thickness $1.6 \mathrm{~cm}$. Annulae were machined from the bulk material by Hedley Louis and Toni Demiris at LLNL such that the axis of each annulus was perpendicular to the casting direction; this was done to try to alleviate as much as possible any variations in density which might occur in the direction of casting (from the bottom to the top of the mold). The dimensions were as follows: outer diameter $4.6 \mathrm{~mm}$, inner diameter $4.0 \mathrm{~mm}$, wall thickness 300 microns, length $10 \mathrm{~mm}$.

\section{Experimenter: Tom Sanford}

Required foam: $50 \mathrm{mg} / \mathrm{cm}^{3}$ agar/gelatin (1:1) doped with $\mathrm{Na}_{2} \mathrm{WO}_{4} \cdot 2 \mathrm{H}_{2} \mathrm{O}$ for the maximum possible level of tungsten; in the form of solid cylinders of I.D. $4.0 \mathrm{~mm}$ and length $25 \mathrm{~mm}$

After some experimentation and information from Bob Morrison, it was determined that the maximum possible level of elemental tungsten in the form of sodium tungstate dihydrate was about $25 \%$-by-mass. For the cylindrical shape, quartz glass tubing with an inside diameter of $4.2 \mathrm{~mm}$ and a length of $26 \mathrm{~mm}$ was cut (oversized to allow for shrinkage). After the hot emulsion was poured into the mold cavities, many pieces of the quartz tubing were placed into the liquid. The portion of foam material within each quartz tube eventually gelled and was frozen and subsequently freeze dried along with the rest of the foam brick. Finally, because of shrinkage and robustness of foam of this density, the product could be pushed out of each piece of quartz tubing after retrieval from within the foam brick. The individual solid foam cylinders were mounted onto target hardware by Mark Vargas for experimental work.

III. Experimenter: Rick Olson

Required foam: $25 \mathrm{mg} / \mathrm{cm}^{3}$ agar/gelatin (1:1) undoped

The foam was produced in the form of bricks with an approximate thickness of $1.6 \mathrm{~cm}$. Small strips of foam of dimensions $3.0 \mathrm{~mm} \times 1.0 \mathrm{~mm} \times 0.5 \mathrm{~mm}$ were cut from the bricks 
for experiments done on the NOVA pulsed power facility at LLNL. First, a layer of foam of the proper thickness $(0.5 \mathrm{~mm})$ was "shaved" from an appropriate brick by means of a modified microtome device. The layer was held firmly on the polished surface of a silicon wafer while pieces of the proper dimensions $(3.0 \mathrm{~mm} \times 1.0 \mathrm{~mm})$ were cut from good material with a new scalpel blade.

\section{Experimenter: Mark Derzon \\ Required foam: $10 \mathrm{mg} / \mathrm{cm}^{3}$ agar/gelatin (1:1) undoped}

The foam material was provided in the form of bricks of approximate thickness $1.6 \mathrm{~cm}$. Annulae were machined from the bulk material by Hedley Louis and Toni Demiris at LLNL such that the axis of each annulus was perpendicular to the casting direction; this was done to try to alleviate as much as possible any variations in density which might occur in the direction of casting (from the bottom to the top of the mold). The dimensions were as follows: outer diameter $1.0 \mathrm{~cm}$, wall thickness $0.5 \mathrm{~mm}$, length $1.0 \mathrm{~cm}$. Figure 11 shows two cross-sectional views of the foam.

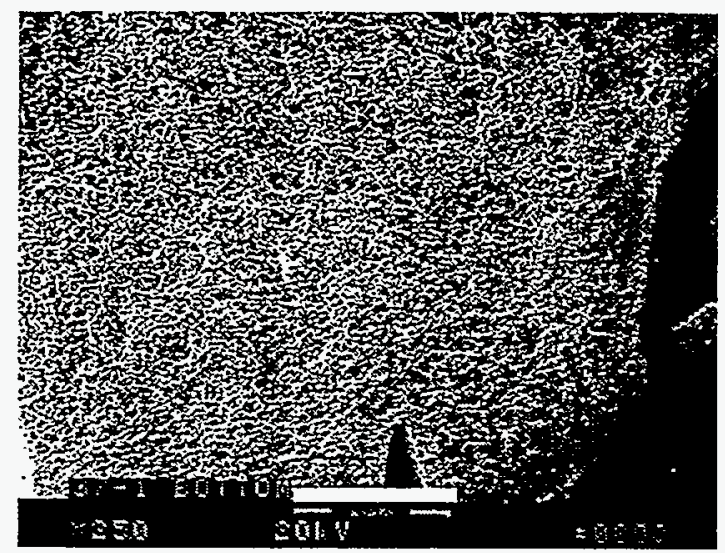

37-1 A

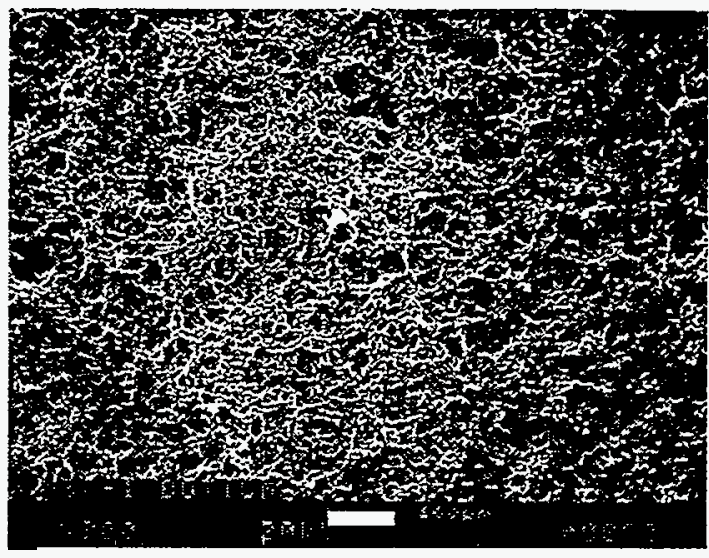

37-1 B

Figure 11. Cross-sectional views of the bottom area of foam 37-1. Left photo: Magnification 25.0, actual length of white bar represents one millimeter on photo; right photo: magnification 100, actual length of white bar represents 100 microns on photo.

\section{FUTURE WORK}

There are numerous efforts that could be made to improve agar/gelatin foams prepared with the processes described in this report. In this section, we summarize the work that we believe would have the largest payoff in terms of improvements in microstructure, strength, and moldability of these foams.

One method to produce foam with more predictable properties is to use starting materials of higher purity and with better defined properties. As mentioned in the section about agar, agarose and gelatin, agarose is essentially a purified form of agar; it is agar without many or most of the large negatively charged anions. In addition to its greater purity, agarose can be obtained with gel strengths far higher than even the highest-gel-strength agar. Therefore, one approach to better defining the entire foam production process would be to 
use agarose with a very high gel strength in combination with gelatin. However, higher gel strength may not translate into better foam materials with higher mechanical strength. In fact, Bob Morrison at LLNL experimented with several agarose starting materials and has stated that the best foams for the range of densities of interest $\left(20\right.$ to $\left.50 \mathrm{mg} / \mathrm{cm}^{3}\right)$ and for the dopants of interest were obtained from agar (bacteriological grade from Polysciences) and gelatin (Knox unflavored food gelatin, available at most grocery stores).

Figure 12 depicts two SEM images of foam 28-1, made form SeaKem Gold® agarose (FMC Bioproducts, no. 50152). Neither gelatin nor dopant were used in this formulation. The solution was made in a manner similar to the procedures given above for the emulsion processes. However, the desired density was $5 \mathrm{mg} / \mathrm{cm}^{3}$ and the surfactant of choice was Merpol A, from DuPont ${ }^{\circledR}$ (10 gm of the liquid surfactant as available from the manufacturer diluted to the mark with deionized water in a 100-ml volumetric flask); it is a non-ionic surfactant and was chosen because the agarose is a relatively non-charged material compared to agar and gelatin. The actual density was approximately $5.8 \mathrm{mg} / \mathrm{cm}^{3}$. The image with lower magnification suggests good uniformity and the image with higher magnification indicates most pores are smaller than 10 microns across. Therefore, agarose alone has shown promise as a foam material. Future development could prove fruitful in this direction.
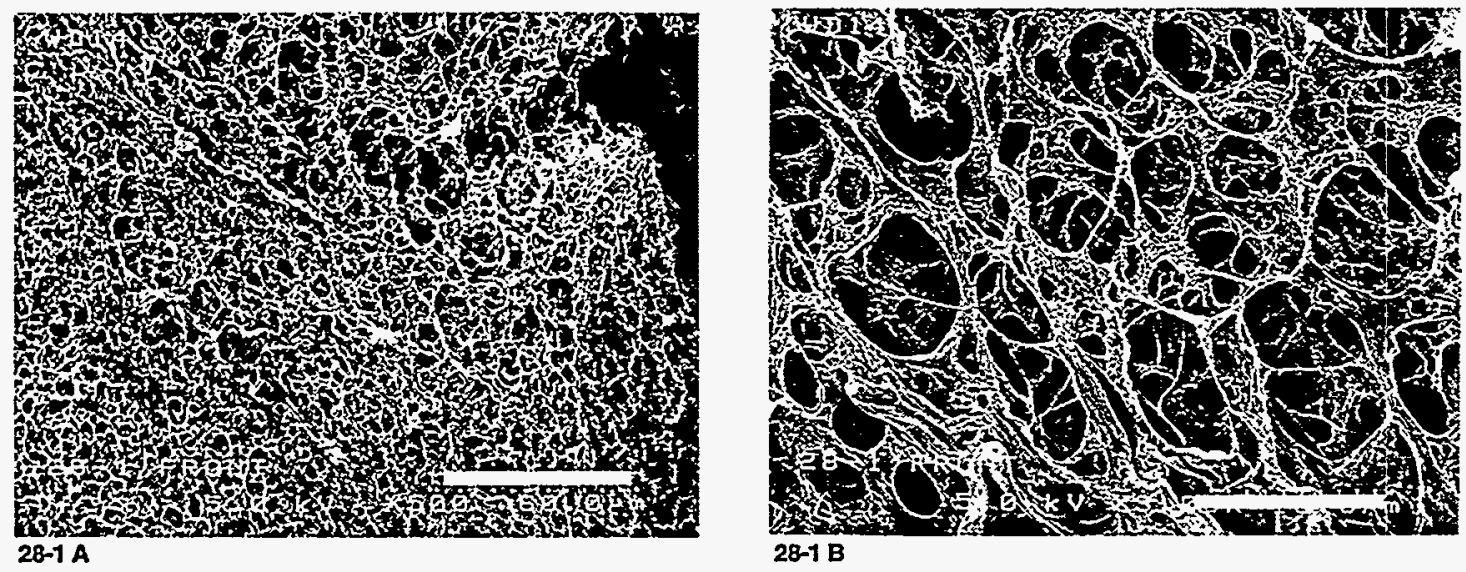

Figure 12. Cross-sectional views of foam 28-1, made of SeaKem Gold@ agarose; target density $5 \mathrm{mg} / \mathrm{cm}^{3}$, actual density $5.8 \mathrm{mg} / \mathrm{cm}^{3}$. The white bars correspond to 10 (right) and 60 microns (left).

Another way to make foam materials of higher quality morphology is to freeze the gels very rapidly in a single direction from the bottom of the mold. The discussion in the section about developments at SNL outlined the details of using a copper cooling block, cooled to the temperature of liquid nitrogen, with a very smooth lapped surface as a heat sink for the mold "box", having its own lapped surface on the bottom for good mechanical contact between the mold box and the cooling block. (A copper cover block having a lapped bottom surface must be placed on top of the main block during cool-down so that a layer of ice does not form.)

Figure 13 shows two images of foam $30-2$; the desired density was $10 \mathrm{mg} / \mathrm{cm}^{3}$ and it was fabricated from a 1:1 mixture of agar and gelatin. However, after gelation, the bricks were frozen on a block of copper cooled to approximately $-190^{\circ} \mathrm{C}$. Many cracking sounds could be heard from the material during freezing but no cracks were evident until the freeze-dry process was complete. This is a problem which would have to be addressed in future 
attempts. In any case, the images show a very good uniform morphology with most of the cells smaller than 10 microns. Furthermore, this material behaved very well when thin layers were "shaved" from a brick with the modified microtome apparatus. The actual density of this foam was estimated at $10.2 \mathrm{mg} / \mathrm{cm}^{3}$. The extremely low temperature of liquid nitrogen may not be necessary for these very good characteristics; perhaps a freezing temperature of $-100^{\circ} \mathrm{C}$ or $-150^{\circ} \mathrm{C}$ would suffice. The copper cooling block arrangement allows convenient and safe access to almost any freezing temperature.

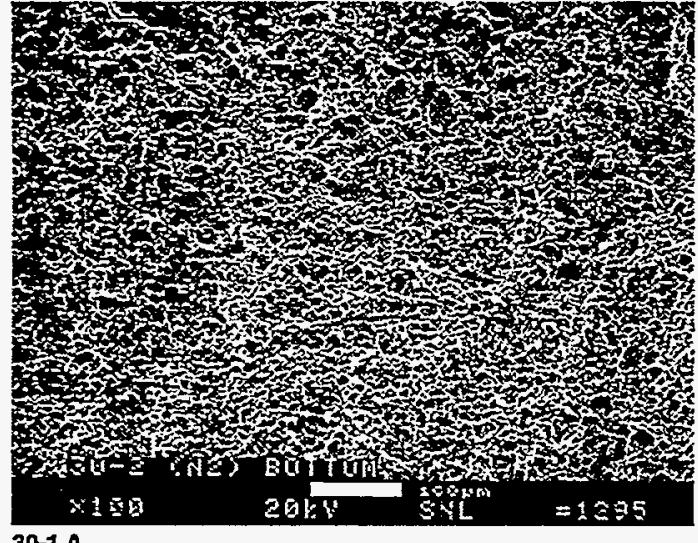

30-1 A

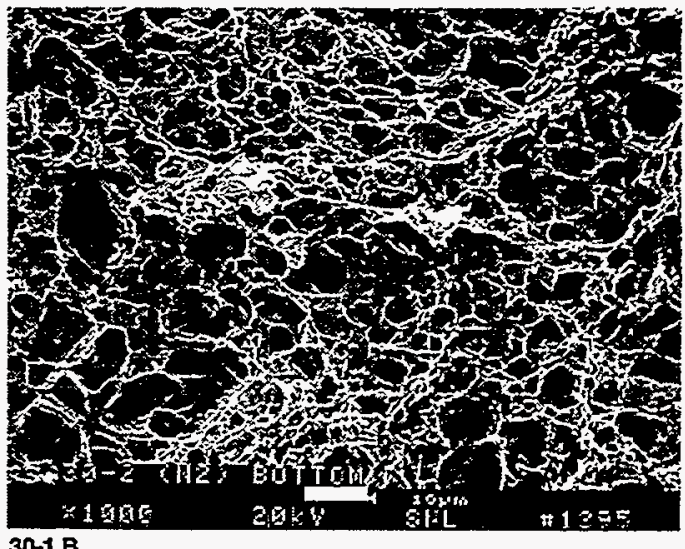

30-1 B

Figure 13. Cross-sectional views of foam 30-2, made from agar/gelatin (1:1) and frozen at liquid-nitrogen temperature. The white bars in the photos represent 100 (left) and 10 microns (right).

Another agarose available from FMC Bioproducts is called SeaPrep® (no. 50302). It has an ultra-low gelling temperature and a gel strength lower than any other agarose and lower than any agar. It was of interest to try this material in order to see what kind of morphology would be produced in a foam. Images of foam 29-1 are shown in Figure 14. The desired density was $5 \mathrm{mg} / \mathrm{cm}^{3}$, actual density was $8.3 \mathrm{mg} / \mathrm{cm}^{3}$; the material did not completely gel before the freezing step. However, the SEM images suggest a "fluid" nature and a surprisingly good morphology, considering the problems encountered with gelation and freezing. Future work with this material could emphasize combination of this agarose with other materials of higher strength so that the final product would be more
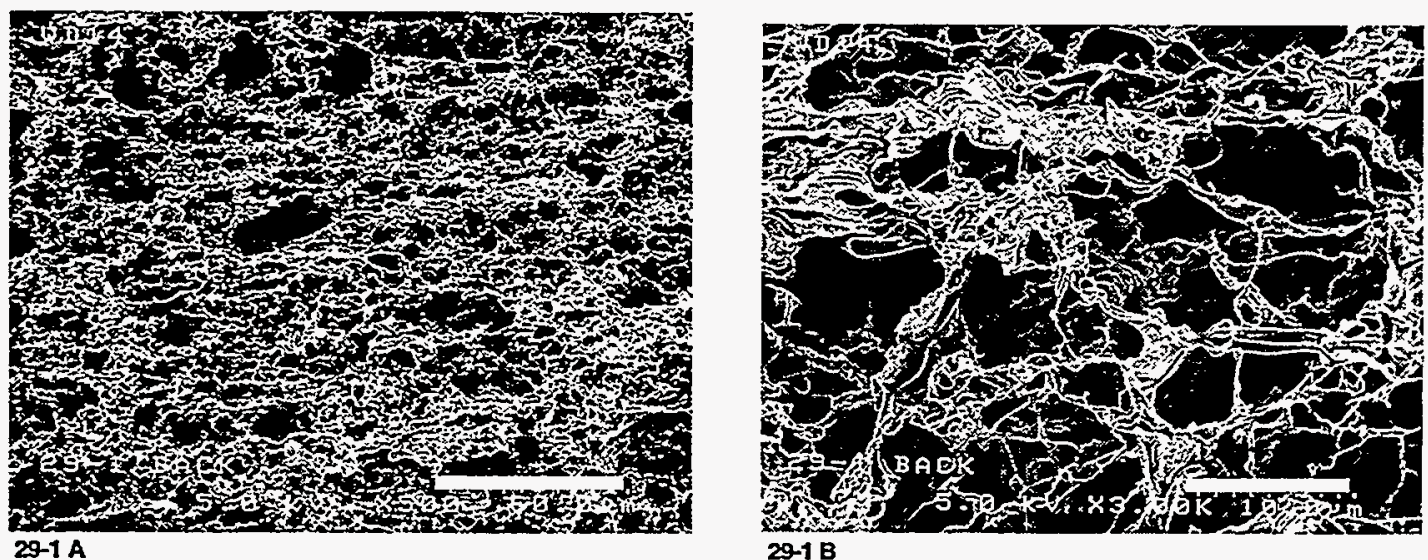

Figure 14. Cross-sectional views of foam 29-1, made of SeaPrep® agarose; the left photo has magnification 500, the right one 3000 . The white bars correspond to 10 (right) and 60 microns (left). 
robust; for example, the SeaPrep® could be combined with SeaKem Gold® agarose described above. In addition, this agarose could prove superior as a dopant medium in combination with gelatin or another type of agarose.

Figure 15 illustrates a foam material (36-1) with very small cell sizes; uniformity is a potential problem in this foam, as seen by the larger cavities and what could be vertical striations formed during the freezing process. The desired density was $10 \mathrm{mg} / \mathrm{cm}^{3}$, actual density was estimated to be $10.7 \mathrm{mg} / \mathrm{cm}^{3}$; it was a mixture (1:1) of gelatin (product $\mathrm{G} 2500$, Sigma Chemical Co.) and a product called NuFix ${ }^{\circledR}$ glyoxyl agarose from FMC Bioproducts. This product was formulated to bind proteins and polypeptides in a biochemical technique called electrophoresis. The glyoxyl agarose contains aldehyde moieties, which will undergo reversible Schiff-base reactions with organic, nucleophilic amines. Above $\mathrm{pH} 8.5$, the equilibrium for such a reaction lies far to the right:

agarose- $\mathrm{O}-\mathrm{CH}_{2}-\mathrm{CH}-\mathrm{O}+\mathrm{R}-\mathrm{NH}_{2} \longrightarrow$ agarose $-\mathrm{O}-\mathrm{CH}_{2}-\mathrm{CH}=\mathrm{N}-\mathrm{R}+\mathrm{H}_{2} \mathrm{O}$

The $\mathrm{RNH}_{2}$ species is found in proteins and in gelatin, which is a polymeric protein or polypeptide.

The basis for using this specialized agarose with gelatin is to create bonds between the two, thus providing a final product with greater strength while maintaining the properties of a foam. The relationship here is not 1:1, since each gram or mole of agarose will fixate only a very small amount of protein. However, the SEM images indicate that a good foam could be obtained from this type of chemistry after some developmental work. The surfactant used to make foam 36-1 was actually a mixture of Triton GR-5M® from Union Carbide, the usual one for agar/gelatin mixtures in these studies, and Merpol $A \circledR$ from DuPont, the non-ionic one to comply with the non-ionic nature of the NuFix® agarose.
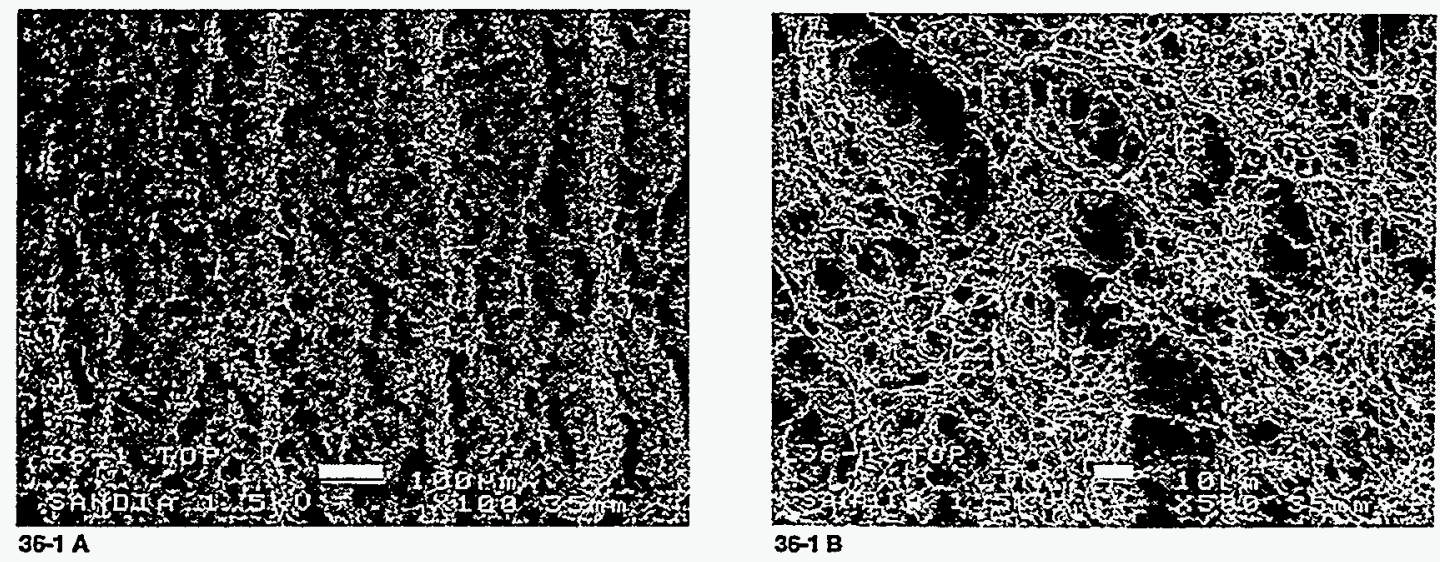

Figure 15. Cross-sectional views of foam $36-1$, made of gelatin/NuFix@ glyoxyl agarose. The bars in the photos represent 100 (left) and 10 microns (right).

In late January 1997, FMC Bioproducts confirmed that they no longer regularly manufacture NuFix ${ }^{\circledR}$ glyoxyl agarose. They make it only as ordered and only in kilogram quantities. This may present a problem for pursuit of this method of obtaining better foam materials. 
There are two additional products from FMC Bioproducts which would merit attention in any future work in obtaining high-quality, low-density foam materials, they are MetaPhorß agarose and IsoGel ${ }^{\circledR}$ agarose. MetaPhor ${ }^{\circledR}$ agarose was formulated to have greater resolution capabilities than other sieving agarose products in biotechnology and biochemical applications; this characteristic may contribute to better overall morphology of a foam. At the writing of this report, no experiments had been performed with this product at SNL. IsoGel® agarose is a highly purified agarose formulated to contain a minimum of fixed anions and mobile cations for a biochemical application called isoelectric focusing. This material may be advantageous for foams which must be doped, since there would be less interaction between the dopant and the anions and cations in the agarose. No investigations of this agarose had been carried out at SNL at the time of this writing.

There are a number of processes which we have identified, but not investigated, that could strengthen agar/gelatin foams through crosslinking mechanisms. These approaches rely on reacting hydroxyl groups (abundant in both agar and gelatin) on adjacent chains. This would be critical to further development of the very low density foams (less than 0.005 $\mathrm{gm} / \mathrm{cm}^{3}$ ). A known method to effect this crosslinking reaction is with an aldehyde, such as formaldehyde, which can react with the hydroxyls in the presence of acid to crosslink adjacent chains ${ }^{21}$. Tests of this approach would require evaluation of the mechanical properties before and after crosslinking. If successful, optimization would involve investigating the aldehyde to be used and whether one would crosslink before or after phase separation. A similar approach would use metal alkoxides (such as tetra ethoxy ortho silicate, TEOS, or titania isopropoxide) and use either acid or base to catalyze the reaction. This would also incorporate the metal into the final foam and hence would result in both crosslinking and simultaneous doping of the foam (Si or Ti for these two chemicals respectively). We have already been successful at doping titania into an agar/gelatin foam with this technique, but did not evaluate crosslinking or mechanical property improvement.

The simplest process to prepare an agar/gelatin foam is the gel freezing process which involves only the following steps: dissolving the agar or agar/gelatin in water at elevated temperature, forming a gel at lower temperature, exchanging the solvent, and freezing and subliming the solvent. For this process, one could optimize the exchange solvent and freezing temperature in order to either minimize cell size, maximize foam strength, or to minimize shrinkage for mold-to-shape applications. The mold-to-shape process could itself be optimized for cylinders or annuli by investigating the solvent, the freezing temperature, mold materials, filling process, and drying process.

\section{ACKNOWLEDGMENTS}

We would like to express our sincere appreciation to Bob Morrison, retired from LLNL, for sharing with us the LLNL technology on agar/gelatin foams through visits and telephone conversations. We appreciate the efforts of Bonnie McKenzie and Gary Zender for the SEM photos, Deanna Sevier and Kyle Thompson for radiography, and especially Hedley Louis and Anthony Demiris, LLNL, for foam machining. We appreciate the funding and technical guidance provided by the pulsed power programs at SNL. 


\section{REFERENCES}

1. T. A. Mehlhorn, Ion Beam Coupling and Target Physics Experiments at Sandia National Laboratories," in "Laser Interaction \& Related Plasma Phenomena," ed by G. H. Miley \& H. Hora, 10 (1992).

2. J. H. Aubert and A. P. Sylwester, "Microcellular foams? Here's How!," CHEMTECH, 21, 290 (1991).

3. J. D. LeMay, R. W. Hopper, L. W. Hrubesh, and R. W. Pekala, "Low-Density Microcellular Materials," MRS Bulletin, p24 (1990).

4. Conversations with Bob Morison, formerly of Lawrence Livermore National Laboratories, Livermore, CA.

5. Manufactured by Ron Simandl, Oak Ridge National Laboratories, Oak Ridge, Tennessee.

6. P. S. Sawyer, P. M. Baca, M. Smith, and J. H. Aubert, "1994 Lithium Thermal Target Assembly Procedure," communication of Sandia National Laboratories, 1994.

7. P. B. Rand and O. J. Montoya, "Molded Ultra-Low Density Microcellular Foams," SANDIA REPORT, SAND86-0638 (1986).

8. M. Ramzi, C. Rochas, and J-M. Guenet, "Phase Behavior of Agarose in Binary Solvents," Macromolecules 29, 4668 (1996).

9. A. Coudeville, P. Eyharts, J. P. Perrine, L. Rey, and R. Rouillard, J. Vac. Sci. Technol. $\underline{18}$ (3),1227 (1981).

10. R.L. Whistler, editor; Industrial Gums, Second Edition, Chapter III, p. 29-48; Academic Press (1973).

11. C. Rochas, M. Lahaye, Carbohydrate Polymers, 10, $289-298$ (1989).

12. P.C. Himenz, Principles of Colloid and Surface Chemistry, Marcel Decker, 1977.

13. A.W. Adamson, Physical Chemistry of Surfaces, John Wiley and Sons, 1976.

14. D.A. Rees, Biochem. J., 126, 257-273 (1972).

15. S. Arnott, et al., J. Mol. Biol., 90, 269-284 (1974).

16. G.A. Griess, et al., Biopolymers, 28, 1475-1484 (1989).

17. Gelatin Manufacturers Institute of America, Inc., New York, New York (1993).

18. A.G. Ward, A. Courts, editors; The Science and Technology of Gelatin; Academic Press, New York, NY (1977).

19. R.L. Morrison, "The Versatile Biofoam Solid," The World \& I, p. 244, November 1992. 
20. D. F. Shriver and M. A. Drezdzon, The Manipulation of Air-Sensitive Compounds, p.109, John Wiley and Sons (1986).

21. Tohru Koide, et al., U.S. Patent \#3,838,957, "Apparatus For Continuously Manufacturing Polyvinyl Acetal Porous Material," Oct. 1, 1974. 


\section{UNLIMITED RELEASE}

\section{INITIAL DISTRIBUTION}

Internal Distribution:

1 MS-1187 R. E. Olson, 9571

1 MS-1193 T. W. L. Sanford, 9531

1 MS-1194 T. J. Nash, 9573

1 MS-1196 M. S. Derzon, 9577

1 MS-1196 T. E. Alberts, 9577

1 MS-1196 D. E. Hebron, 9577

10 MS-1407 J. H. Aubert, 1815

10 MS-1407 W. F. McNamara, 1832

1 MS-1435 H. J. Saxton, 1800

2 MS-0619 Review and Approval Desk, 12690 For DOE/OSTI

5 MS-0899 Technical Library, 4414

1 MS-9018 Central Technical Files, 8940-2

External Distribution:

Hedley Louis

Research Mechanical Engineer

Lawrence Livermore National Laboratories

University of California

PO Box 808

Livermore, CA 94551 